\title{
Benefit-Risk Assessment of Crataegus Extract WS 1442: An Evidence-Based Review
}

\author{
Christian J. F. Holubarsch ${ }^{1}$ Wilson S. Colucci ${ }^{2} \cdot$ Jaan $_{\text {Eha }^{3}}$
}

Published online: 28 October 2017

(c) The Author(s) 2017. This article is an open access publication

\begin{abstract}
Preparations from Crataegus (hawthorn) have a long history in the treatment of heart failure. WS 1442 is a dry extract from hawthorn leaves with flowers (4-6.6:1), extraction solvent of ethanol $45 \%(\mathrm{w} / \mathrm{w})$, adjusted to $17.3-20.1 \%$ of oligomeric procyanidins. Nonclinical studies show that WS 1442 has positive inotropic and antiarrhythmic properties and protects the myocardium from ischemic damage, reperfusion injury, and hypertensionrelated hypertrophy, improves endothelial functions such as NO synthesis, and delays endothelial senescence. Randomized, controlled trials in patients with heart failure have demonstrated that the herbal medicinal product increases functional capacity, alleviates disabling symptoms, and improves health-related quality of life, all of which have become important targets of heart failure therapy according to current disease management guidelines. Clinical trials (including a 2-year mortality study with polypharmacy and $>1300$ patients exposed) and post-marketing surveillance studies have shown that WS 1442 has a very favorable safety profile both as monotherapy and as add-on therapy, where no drug interactions have been observed. No specific adverse reactions to WS 1442 are known to date. WS 1442 may thus help to close the therapeutic gap between systolic and diastolic heart failure for which evidence of efficacy for other
\end{abstract}

Christian J. F. Holubarsch

c.holubarsch@park-klinikum.de

1 Park-Klinikum Bad Krozingen, Herbert-Hellmann-Allee 38, 79189 Bad Krozingen, Germany

2 Cardiology Department, Boston Medical Center, Boston, USA

3 Department of Cardiology, University of Tartu, L. Puusepa 8, 51014 Tartu, Estonia cardioactive drugs is sparse. Scientific evidence shows that WS 1442 is safe and has a beneficial effect in patients with heart failure corresponding to New York Heart Association classes II or III. The benefit-risk assessment for WS 1442 is therefore positive.

\section{Key Points}

WS 1442 has been shown to be effective in reducing symptoms, increasing the functional capacity, and improving the quality of life of patients with New York Heart Association class II or III heart failure.

Several clinical trials have demonstrated the safety of WS 1442 in patients suffering from heart failure, including those with concomitant use of other comedications like $\beta$-blockers, angiotensin-converting enzyme inhibitors, diuretics, and cardiac glycosides (digoxin and digitoxin).

Further clinical trials have demonstrated that WS 1442 has a positive benefit-risk assessment for the treatment of heart failure with preserved and reduced ejection fraction.

\section{Introduction}

The phrase "first do no harm" has been ascribed to Hippocrates (about 460-370 B.C.), but was actually coined by the British physician Thomas Inman as recently as 1860 $[1,2]$. The intention behind the dictum is to remind 
physicians that they ought to always act in the best interest of their patients. Most medical treatments are inevitably associated with certain risks to the patient; these consequences may be more or less serious and more or less likely to occur depending on the patient and his/her circumstances. Physicians and patients may nevertheless be inclined to accept certain treatment emergent risks if they are outweighed by the expected therapeutic benefit. It is therefore important to assess the over-all risk-benefit ratio of any medical treatment.

Preparations from leaves and flowers of certain species of Crataegus (hawthorn) have been mentioned as remedies in the medical literature since the 1st century A.D. [3], mainly for treating cardiac diseases and for strengthening the aging heart. In 1896, 43 cases of patients suffering from various forms of heart disease and treated with Crataegus oxyacantha were reported, with promising results [4]. But it was not until the 1930s that systematic scientific research into the clinical effects of Crataegus preparations started, and extracts from Crataegus were introduced into the German pharmacopoeia in 1941. In 1984 and 1994, the German Commission E issued positive monographs for Crataegus leaves with flowers [5] for the treatment of decreasing functional capacity of the heart corresponding to class II of the New York Heart Association (NYHA) Functional Classification, which is characterized by mild cardiac symptoms such as fatigue, palpitation, dyspnea, or anginal pain during ordinary activity [6]. As medicinal products containing Crataegus leaves and flowers have been in use for at least 30 years ( 15 years within the EU), in 2016, the European Medical Association (EMA), through the Committee on Herbal Medicinal Products (HMPC), recognized the traditional use of Crataegus for the relief of symptoms of temporary nervous cardiac complaints (after serious medical conditions have been excluded) [7]. Regarding the safety profile of this product, the EMA concluded that the use of Crataegus leaves and flowers can be regarded as safe when used under the approved indications [8].

WS $1442^{1}$ is a dry extract from hawthorn leaves with flowers (4-6.6:1), extraction solvent of ethanol 45\% (w/w). The extract is adjusted to $17.3-20.1 \%$ oligomeric procyanidins (OPCs). In addition to OPCs, the extract contains several flavonoids, including hyperoside, vitexin-rhamnoside, rutin, and vitexin as well as triterpenoids and phenol carboxylic acids. WS 1442 complies with the requirements of the European pharmacopoeia.

The safety and efficacy of Crataegus containing products have been studied and reviewed extensively [9, 10], and WS 1442 is probably the most rigorously studied

\footnotetext{
$\overline{{ }^{1} \mathrm{WS}^{\circledR} 1442}$ is the active substance of Crataegutt ${ }^{\circledR}$ (Dr. Willmar Schwabe GmbH \& Co. KG, Karlsruhe, Germany).
}

extract on the market. This work provides a comprehensive overview of the safety and efficacy of WS 1442 in NYHA class II and III heart failure and assesses the risk-benefit ratio of the product, also considering different types of heart failure, i.e., systolic heart failure [heart failure with reduced ejection fraction (HFrEF)] and diastolic heart failure [heart failure with preserved ejection fraction (HFpEF)].

\section{Pharmacology and Nonclinical Data, Mode of Action}

In vitro experiments with human myocardial tissue demonstrated a positive inotropic effect of WS 1442 and a concentration-dependent increase of myocardial contractility accompanied by a transient rise in intracellular calcium $[11,12]$. The effect is likely mediated by cyclic adenosine monophosphate (cAMP)-independent inhibition of sodiumpotassium-ATPase, and is accompanied by an improved energy turnover of myocytes [12-14]. In contrast to cardiac glycosides, WS 1442 prolongs the action potential and the refractory period, and possesses pronounced anti-arrhythmic properties [15]. WS 1442 enhances the relaxant effect of the nitric oxide (NO) donor nitroprusside and increases the release of NO from the endothelium while possibly inhibiting the NO degradation due to the antioxidative properties of WS 1442 [16]. The extract causes endothelium-dependent vasorelaxation by an NO-mediated mechanism via endothelial NO synthase (eNOS)-phosphorylation at serine $1177[17,18]$. Increased endothelial NO availability delays activation of the local angiotensin system and endothelial senescence [19]. Endothelium-derived hyperpolarizing factor contributes to the vasorelaxing activity of WS 1442, most likely due to reduced vascular oxidative stress [20]. Moreover the compound enhances microcirculation by reducing endothelial surface layer height and stiffness [21] as well as by increasing red blood cell (RBC) NO formation [22] and RBC surface negativity [23]. Chronic administration of WS 1442 leads to a dose-dependent increase in myocardial basal vessel blood flow [24] and prevents deoxycorticosterone acetate (DOCA) salt-induced hypertension and alterations of cardiac, vascular, and renal structure and function [25].

In animal models of short-term ischemia and reperfusion, WS 1442 caused a significant reduction of ventricular fibrillation, tachycardia, and hypotensive crisis [15, 26]. Protection against reperfusion injury as well as reduction of ST segment elevation after reperfusion and ventricular fibrillation, infarct size, and mortality were also observed in rats [27]. An increased coronary blood flow as well as reduced endothelial dysfunction, inhibition of lipid oxidation and anti-inflammatory properties may contribute to the 
cardioprotective effects of WS 1442 [28]. Sustained, maladaptive cardiac hypertrophy related to physiological stimuli, such as hypertension, valvular disease, or myocardial infarction, has been recognized as a leading cause of cardiac insufficiency [20]. WS 1442 lowered the hypertensive blood pressure and inhibited the development of cardiac hypertrophy in rats, while it had no effect in normotensive control animals $[25,29]$. In pressure overload-related cardiac hypertrophy, a reduction of enlarged left ventricular chamber volume and augmented wall thickness was observed [30, 31].

In a rat model of endotoxin shock, WS 1442 significantly reduced the deterioration of cardiac output and prevented an increase in peripheral resistance. Since the extract did not affect peripheral blood pressure or heart rate, the increased cardiac output is presumably related to improved ventricular diastolic filling and enhanced myocardial contractility [32]. There is pre-clinical evidence that WS 1442 may have a beneficial effect on human lipid metabolism [9]. For example, an in vitro experiment using human Hep-G2 cells showed that WS 1442 causes a dose-dependent inhibition of apolipoprotein-B secretion and thereby decreases the formation of oxygenated lowdensity lipoprotein (LDL), from which a prophylactic effect against atherosclerosis may be expected [33, 34].

Most of the beneficial effects of WS 1442 on the myocardium, notably its cardioprotective properties, are closely related to the OPC to which the extract is adjusted $[16,27,28]$.

Hecker-Niediek [35] determined the absorption and distribution of the radioactivity of ${ }^{14} \mathrm{C}$-labeled catechins, a trimeric procyanide, an OPC total fraction and higher OPCs after intravenous and oral administration in mice. Total radioactivity was measured in blood and different organs without determination of individual metabolites. One hour after oral administration, absorption of radioactivity could already be detected for all labeled substances. The absorption rate for the OPC total fraction was about $31 \%$, and the rates for individual substances ranged from 16 to $40 \%$. After repeated oral administration, the accumulation of radioactivity was higher than after a single dose.

In studies conducted with rats, WS 1442 doses of up to $3000 \mathrm{mg} / \mathrm{kg}$ body weight did not cause any chemical, hematological, morphological, or histological abnormalities or genotoxicity and had no influence on peri- or postnatal development [9].

\section{Clinical Safety and Tolerability}

A comprehensive systematic review of the safety profile of Crataegus species, covering all clinical studies and postmarketing surveillance projects with hawthorn monopreparations published in or before January 2005, was presented by Daniele et al. [36]. The authors identified 14 studies with WS 1442, of which ten were randomized, controlled trials, two were uncontrolled trials, one was an observational study, and one was a cohort study. In these projects, a total of 1563 subjects (controlled clinical trials: 395; uncontrolled studies: 1168) were exposed to the herbal medicinal product and received daily doses of up to $1800 \mathrm{mg}$ for treatment periods of up to 16 weeks in clinical trials and 2 years in post-marketing surveillance projects. One trial was performed in healthy volunteers, while the participants of all other studies suffered from heart failure corresponding to NYHA classes I-II or II-III.

In the randomized trials included in the review and presenting data on adverse events (AEs), 30 of 356 patients treated with WS 1442 and 34 of 299 receiving placebo or a reference drug reported AEs with any causal relationship. In the trials reviewed, $\mathrm{AE}$ incidence in patients treated with WS 1442 was generally on a placebo level. There was no apparent relationship between WS 1442 dose and AE manifestation. In one double-blind study investigating daily doses of 1800 and $900 \mathrm{mg} /$ day WS 1442 compared to placebo during 16 weeks of treatment, the proportions of patients with any AEs were 26.1, 28.6, and 51.4\%, respectively, and therefore lower in patients treated with WS 1442 than in placebo-treated patients [37]. The authors of the review interpreted this result to be an indicator of treatment efficacy rather than of safety, since WS 1442 appears to prevent, rather than elicit, symptoms like dizziness that are frequently reported as AEs [36]. In an observational study included in the review, which monitored 1011 patients with heart insufficiency stage NYHA II treated with WS 1442 over a period of 24 weeks, $98.7 \%$ of physicians noted a "good" or "very good" tolerance to the treatment, with only 14 AEs [38]. Moreover, in any of the studies reviewed, none of the AEs potentially related to WS 1442 were serious.

One of the merits of the review of Daniele et al. [36] is that their search strategy assured a comprehensive overview of the literature available at the time of its publication regarding potential risks associated with Crataegus extract. Limitations include the lack of a comprehensive overview of the study selection criteria and of an assessment of the methodological quality and validity of the trials (the authors appear to have accepted all identified studies conducted with Crataegus monopreparations irrespective of their methodological quality, unless they were duplicate publications of other work). Since the publication of the review, additional clinical trials involving WS 1442 have been published:

The SPICE (Survival and Prognosis: Investigation of Crataegus Extract WS 1442 in congestive heart failure) trial reported by Holubarsch et al. [39, 40] was a placebo- 
controlled, double-blind, multicenter trial in which 2681 adults with NYHA class II or III congestive heart failure and reduced left ventricular ejection fraction (LVEF $\leq 35 \%)$ were randomized to receive $900 \mathrm{mg}$ /day WS $1442(n=1338)$ or placebo $(n=1343)$ for a total duration of 24 months. At baseline, the average LVEF was $24 \%$, and thus a substantial percentage of the study participants were at a high risk of cardiac mortality. WS 1442 was administered as an add-on treatment to guideline cardiac medication, and thus digoxin or digitoxin, diuretics, $\beta$ blockers, and angiotensin-converting enzyme (ACE) inhibitors were permitted as concomitant medication in any clinically appropriate combination or dose. In fact, about $90 \%$ of the study participants took at least three concomitant cardioactive drugs: about $85 \%$ of the patients in each group were administered diuretics, $83 \%$ received ACE inhibitors, $64 \%$ were treated with $\beta$-blockers, and $56 \%$ were administered digitalis or nitrates; concomitant antiarrhythmics were used by about $22 \%$ of the study participants, implicating possible proarrhythmic effects [41, 42].

With a sample size of about 1340 patients in each group, the SPICE study had a $95 \%$ chance of observing at least one $\mathrm{AE}$ whose true incidence in the population is at least $2.2 \%$ and was thus suited for observing even less frequent complications or drug-drug interactions. During the 2-year follow-up, $67.0 \%$ of the patients randomized to WS 1442 and $68.3 \%$ of those in the placebo group reported AEs, corresponding to one event in 388 and 370 days of exposure, respectively. Serious AE rates were 39.2 and $41.1 \%$, respectively. The types of AEs were very similar in both treatment groups, and no specific AEs related to WS 1442 were observed [40].

The Hawthorn Extract Randomized Blinded Chronic Heart Failure (HERB CHF) trial published by Zick et al. $[43,44]$ investigated the effect of 6 months' randomized, double-blind, add-on therapy with WS 1442 or placebo on submaximal exercise capacity in patients with NYHA class II-III chronic heart failure. A total of 120 patients participated, 60 of whom received WS 1442. Any AEs were experienced by 36 patients in the WS 1442 group (60.0\%) and by 23 patients (38.3\%) in the placebo group. However, 12 patients in each group (20.0\%) reported cardiac-related AEs, and their incidences as well as those of common AEs like infections, rash, gastrointestinal complaints, and headache were also comparable. The authors concluded that the difference in the over-all $\mathrm{AE}$ rate was unlikely explainable by a pharmacological effect of WS 1442 and may have been attributable to chance. Zick et al. [44] also observed a higher rate of heart failure progression (composite secondary endpoint of death, hospitalization, and increased diuretic use) in the early phase of the trial under WS 1442 as compared to placebo, although the difference disappeared in the course of the 6-month follow-up. The authors interpret this as an indicator that WS 1442 could increase the early risk of heart failure, but also warn that these findings could be due to chance and must be interpreted with caution, since they come from a post hoc analysis of an outcome measure not pre-specified before unblinding, which was performed in a relatively small study (120 patients) with a limited absolute number of heart failure events (28/60 and 26/60 patients for WS 1442 and placebo, respectively). The results of Zick et al. [44] are also not supported by the SPICE trial [40], in which 2681 patients were observed for up to 2 years. In contrast to Zick et al. [44], the heart failure hazards in the SPICE trial were proportional over time, and no signals for an increased risk of heart failure under treatment with WS 1442 were observed, neither during the initial months of treatment, nor at any other time during follow-up.

Another randomized, controlled, exploratory trial was performed by Härtel et al. to investigate the effect of endurance exercise training and add-on medication with WS 1442 in patients with HFpEF meeting NYHA class II criteria [45]. A total of 140 patients on guideline cardiac medication received 8 weeks of aerobic endurance training, and 70 of them were randomized to additional, openlabel administration of $900 \mathrm{mg} / \mathrm{day}$ WS 1442 . AEs with any causal relationship were observed in nine patients in the WS 1442 group (12.9\%) and in 12 patients in the control group (17.1\%). Most events were musculoskeletal complaints and injuries (possibly related to exercise training) and infections. None of the events reported in the WS 1442 group were assessed to be related to the herbal medicinal product.

Signals for possible drug interactions with WS 1442 were not observed in any of the studies reviewed by Daniele et al. [36], nor in those published after completion of their review [40, 43, 45], nor in literature searches that also included spontaneous reports to health authorities about suspected adverse reactions to hawthorn containing products $[9,46]$. In a randomized, crossover, interaction study in healthy volunteers, concurrent administration of WS 1442 had no effect on the pharmacokinetic properties of digoxin [47].

\section{Clinical Efficacy}

Treatment of heart failure is aimed at reducing morbidity and hospitalization as well as at improving heart failure emergent symptoms and health related quality of life (QoL). While trials investigating the efficacy of treatment in heart failure have previously focused mainly on mortality, current heart failure disease management guidelines increasingly recognize the importance of improving 
symptoms and QoL as patient-relevant outcomes. An example of this shift is a change in the description of the objectives of heart failure treatment between the European Society of Cardiology "Guidelines for the Diagnosis and Treatment of Acute and Chronic Heart Failure" of 2008 and 2012: whereas in the 2008 document it is stated that "The purpose of diagnosing and treating heart failure is no different from any other medical condition, namely to bring about a reduction of mortality and morbidity" [48] (p. 2404), the authors of the 2012 revision recognize that "The goals of treatment in patients with established heart failure are to relieve symptoms and signs ..., prevent hospital admission, and improve survival" [49] (p. 1804). In addition to improving survival and reducing hospitalization, the relief of symptoms such as dyspnea, fatigue, tiredness, or edema, as well as improvement in QoL and an increase in functional capacity, are thus also of the utmost importance to patients [50]. Moreover, a lack of improvement in health-related QoL after hospital discharge has been identified as a powerful predictor of re-hospitalization and mortality [51].

\subsection{Survival}

The effect of WS 1442 on mortality and hospitalization in NYHA class II-III HFrEF was investigated in the SPICE study, a 24-month, randomized, placebo-controlled trial $[39,40]$. The primary endpoint was the time until the first cardiac event, defined as a composite endpoint of death of cardiac cause, non-fatal myocardial infarction, or hospitalization due to progressive heart failure. During 2 years of treatment, cumulative first cardiac event rates were lower with WS 1442 compared to placebo, albeit without reaching statistical significance (Fig. 1). Moreover, participants treated with WS 1442 were at a lower cumulative risk of cardiac mortality and sudden cardiac death (Fig. 2), notably in patients with baseline LVEF between 25 and $35 \%$ (upper limit for inclusion). In this subset, the difference with respect to placebo was descriptively significant at months 12, 18, and 24 in favor of WS 1442 for sudden cardiac death (Fig. 3). The results point to a potential antiarrhythmic and/or anti-ischemic effect already observed in animal models, where WS 1442 prevented reperfusion arrhythmias effectively. This is particularly important considering adverse reactions to chemical antiarrhythmics including amiodarone, since the reduction of the risk of sudden cardiac death was accomplished by WS 1442 without observing adverse reactions.

\subsection{Quality of Life and Exercise Tolerance}

The effect of WS 1442 on symptoms of heart failure and QoL-related outcomes was investigated in several smaller

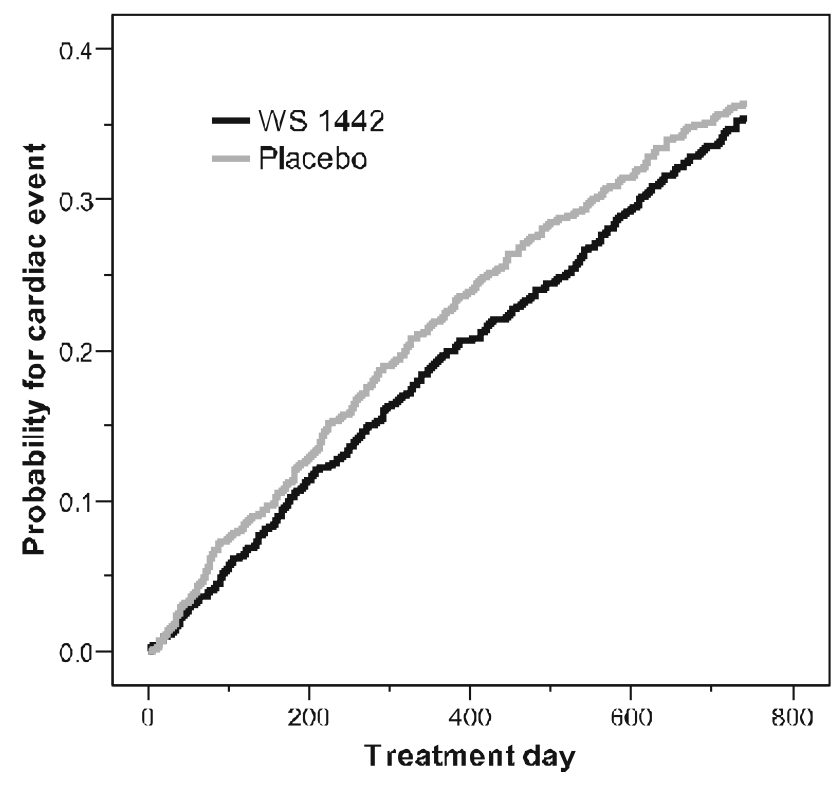

Fig. 1 Cumulative hazard for time to first cardiac event (from [40])

trials, most of which were included in a Cochrane review of hawthorn extracts for treating chronic heart failure [52]. The authors identified 28 and included 14 trials which were performed in patients using a hawthorn monopreparation and which were randomized and placebo controlled. Of the 14 eligible trials, 11 used WS 1442, while three used LI 132, a methanolic extract standardized to a content of $2.2 \%$ flavonoids. For WS 1442, the effect on symptoms and/or health-related QoL was also investigated in controlled studies completed only after finalization of the Cochrane review [40, 43, 45].

Exercise tolerance tests were performed in four trials included in the Cochrane review [37, 53-55]. A metaanalysis of maximum workload (Fig. 4), in which the WS 1442900 and $1800 \mathrm{mg}$ /day groups investigated by Tauchert [37] were analyzed separately, showed a statistically significant increase over placebo by a weighted mean difference of $5.4 \mathrm{~W}$ [95\% confidence interval (CI) $0.7-10.0, p=0.024]$. Moreover, based on a meta-analysis of two trials $[54,55]$, the exercise tolerance was increased significantly by a weighted mean difference of $122.8 \mathrm{~W}$ min (95\% CI 32.7-212.8, $p<0.01)$.

The pressure-heart rate product, an index of cardiac oxygen consumption, was assessed in five trials included in the Cochrane review [55-59] and performed with WS 1442. Compared to placebo, meta-analysis showed a significant reduction of the pressure-heart rate product in WS 1442-treated patients by a weighted mean difference of $19.2 \mathrm{mmHg} / \mathrm{min}(95 \% \mathrm{CI} 8.0-30.5, p<0.01)$ as well as significant reductions in four of the five primary trials [52]. The results indicate a significant increase in cardiac performance in patients treated with WS 1442. 
Fig. 2 Cumulative hazard for cardiac mortality (a, c) and sudden cardiac death $(\mathbf{b}, \mathbf{d})$ : all patients $(\mathbf{a}, \mathbf{b})$ or patients with $\mathrm{LVEF} \geq 25 \%(\mathbf{c}, \mathbf{d})$ (from [40]). $L V E F$ left ventricular ejection fraction

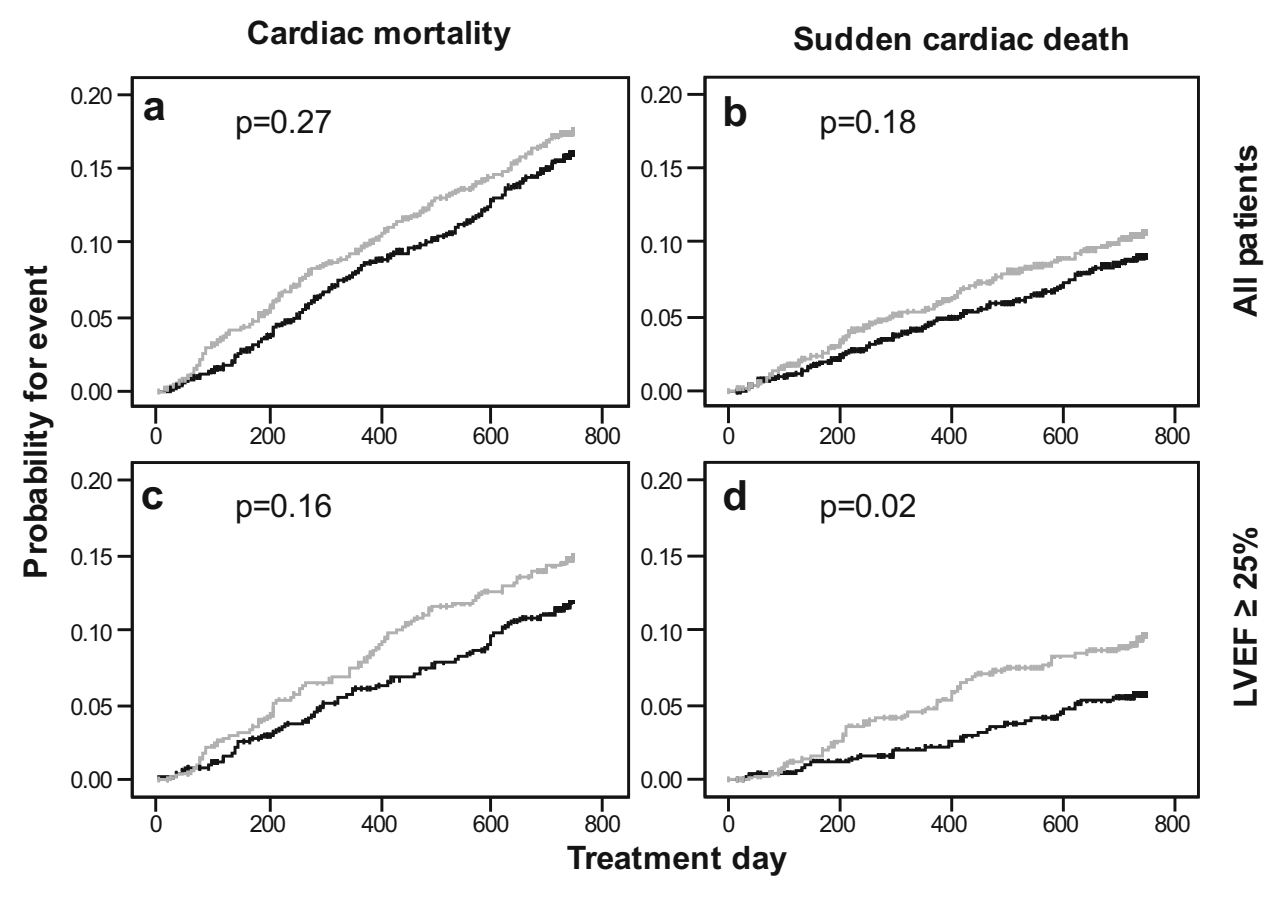

— WS 1442 - Placebo

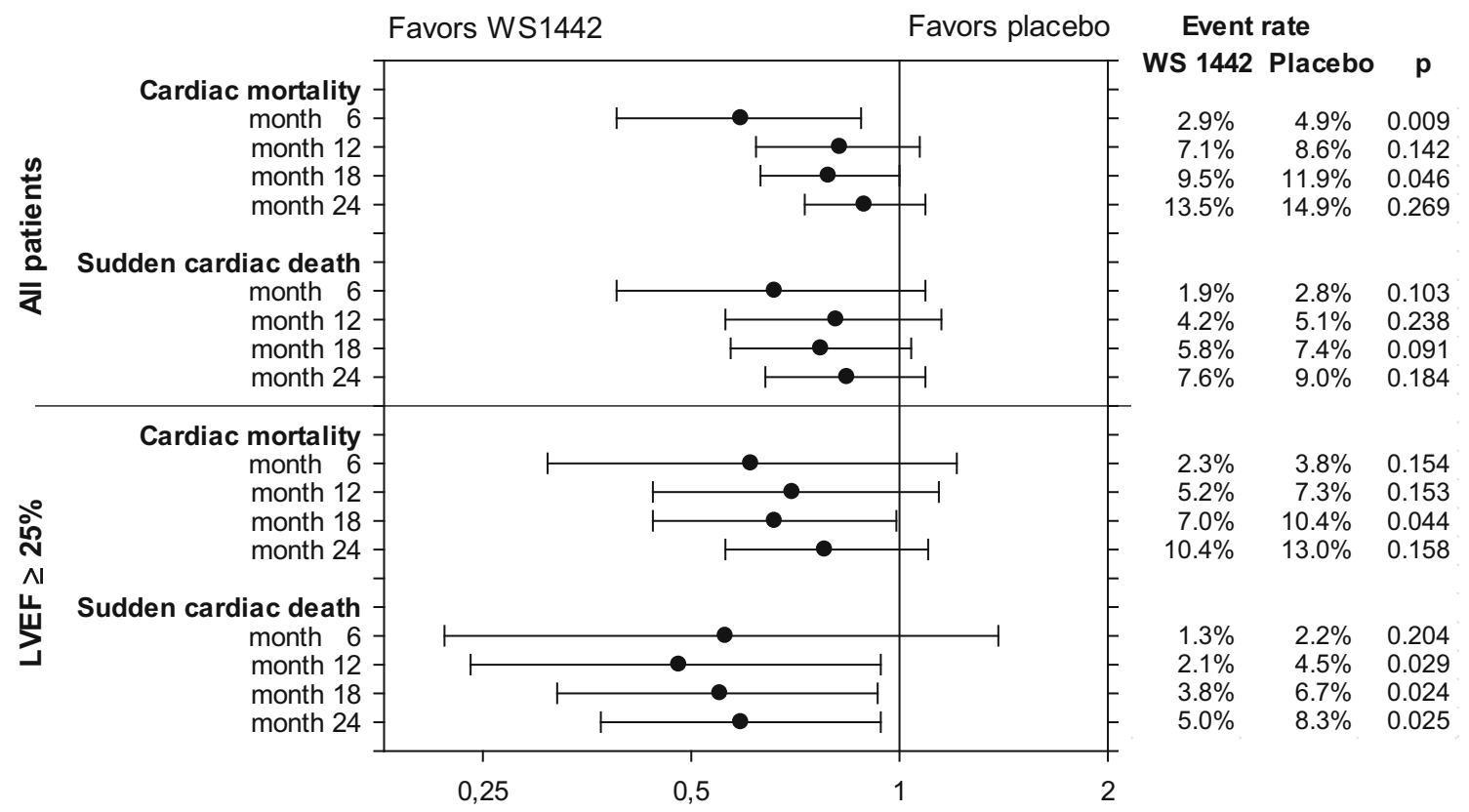

Fig. 3 Cardiac mortality and sudden cardiac death in total population and subgroup LVEF $\geq 25 \%$ (hazard ratios, 95\% confidence intervals and two-sided log-rank test $p$ values) (from [40]). $L V E F$ left ventricular ejection fraction

In patients with HFrEF, Eichstädt et al. [60] as well as Zick et al. [43] observed improvements of reduced LVEF, with moderate but statistically significant advantages for WS 1442 over placebo $(p<0.01$ and $p=0.04$, respectively).
In the trial performed by Härtel et al. [45] in 140 patients with HFpEF, in which 8 weeks of exercise training (biweekly, 90-min, supervised training sessions and aerobic walking) alone (70 patients) was compared to exercise training plus 900 mg WS 1442 per day, physical exercise capacity was analyzed by a $2-\mathrm{km}$ walking test performed at 
Fig. 4 Maximum workload (W): meta-analysis of difference between Crataegus and placebo for change from baseline (means and 95\% confidence intervals, random effects model) Data from [52], Fig. 1.1, based on studies reported by Bödigheimer and Chase [53] (LI 132), Hanak and Brückel [54], Tauchert [37] and Zapfe [55] (all WS 1442)

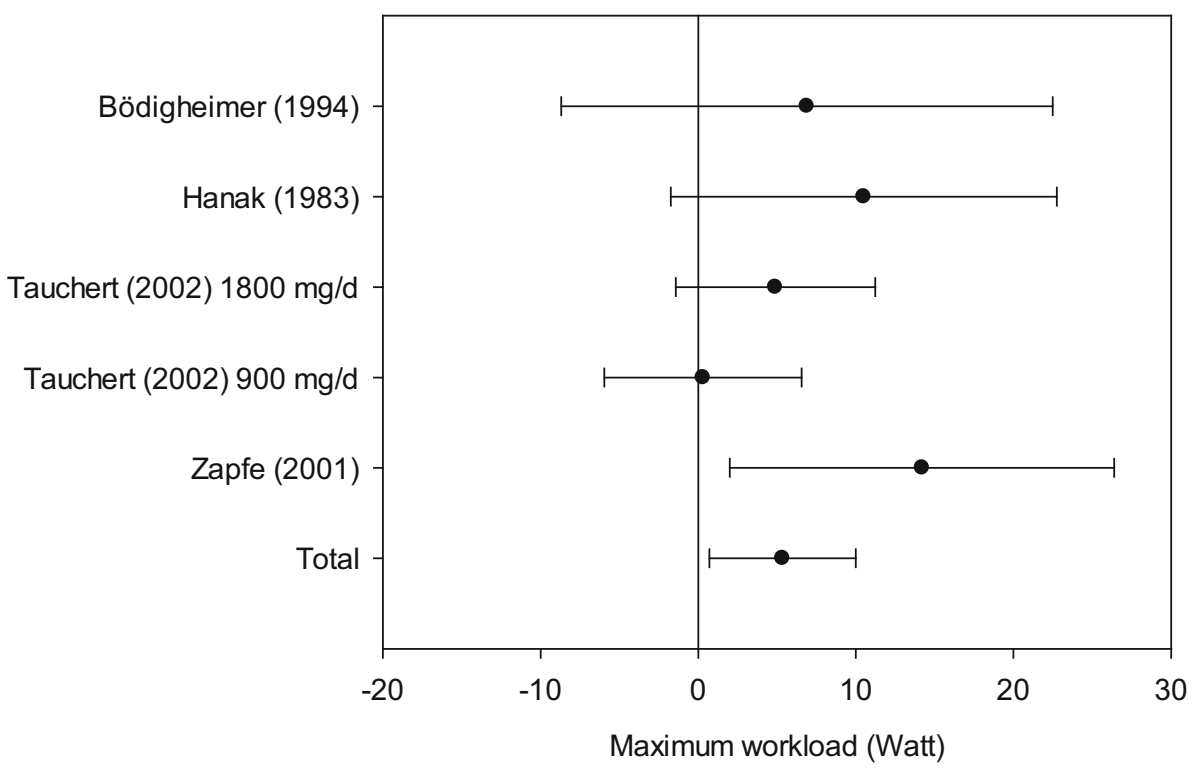

baseline and treatment end (70 patients). Whereas patients randomized to WS 1442 showed a reduction of the time needed to accomplish the 2-km distance from an average of 23.0 to $20.1 \mathrm{~min}$ (reduction of $12.7 \%$ of the baseline value), the patients in the control group showed a reduction from 21.4 to $19.6 \mathrm{~min}(-8.4 \%)$. The difference was statistically significant $(p=0.02$; Fig. 5$)$. In patients with HFrEF, Zick et al. [43] found an increase in 6-min walking distance from an average of 358 to $371 \mathrm{~m}$ for WS 1442 and from 374 to $379 \mathrm{~m}$ for placebo, but the difference was not significant at the $5 \%$ level.

Changes in heart failure-associated symptoms and health-related QoL during treatment with WS 1442 were assessed in several trials $[37,43,45,56,57]$. In two trials,

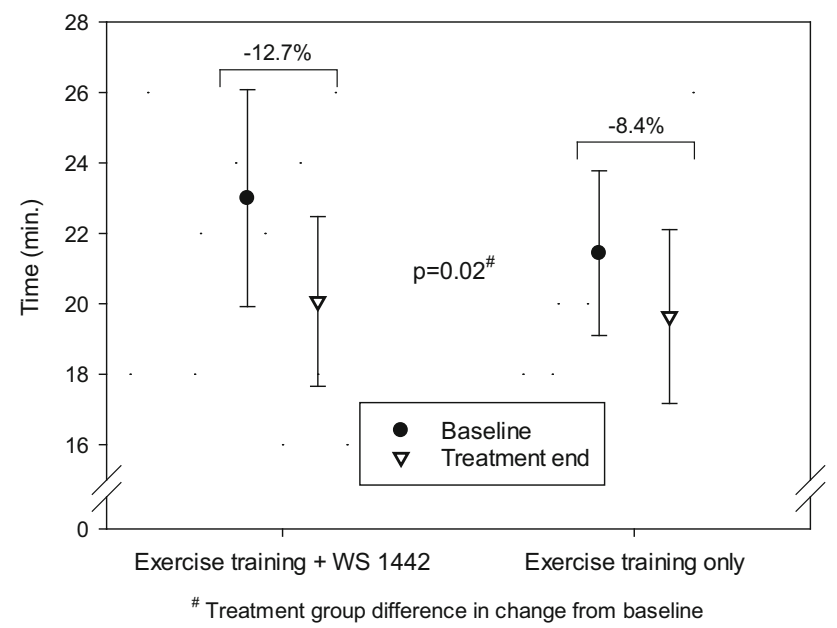

Fig. 5 Time for 2-km walking test (means and standard deviations; data from [45]) the von Zerssen Complaints List [61], a validated selfrating questionnaire assessing 24 general symptoms, some of which (e.g., shortness of breath, fatigue) are particularly important in heart failure, was used. In the study reported by Leuchtgens [56], which included 30 patients (15 per group), those treated with WS 1442 for 8 weeks showed a significantly more pronounced decrease of the total score of the scale than those in the placebo group (mean value difference 7.3 points, $95 \%$ CI $0.9-13.7$, according to [52]). In the study of Tauchert [37] in which 209 patients received 1800 or $900 \mathrm{mg} /$ day WS 1442 or placebo for 16 weeks, both WS 1442 dosages showed a significantly more pronounced total score decrease compared to placebo (Fig. 6).

Tauchert [37] also used an ad hoc score assessing the four "typical" heart failure symptoms, i.e., general capability, lassitude, early fatigability, and effort dyspnea. At the end of the 16-week treatment phase, the treatment group differences to placebo for score change versus baseline were significant for WS $1442900 \mathrm{mg} /$ day $(p=0.04)$ and $1800 \mathrm{mg} /$ day $(p=0.004)$.

Weikl et al. [57] used a health-related QoL inventory developed by Siegrist and Junge [62] for chronically ill patients and including items focusing on functional capacity (symptom burden, ability to enjoy and relax, positive and negative mood, sociableness, and allegiance). The authors report on a trend towards more pronounced improvement of all symptoms assessed in patients treated with WS 1442 as compared to placebo. During the baseline examination, the 136 patients included in the trial were also asked to identify and rate their main symptoms and complaints associated with heart failure. After 8 weeks of 


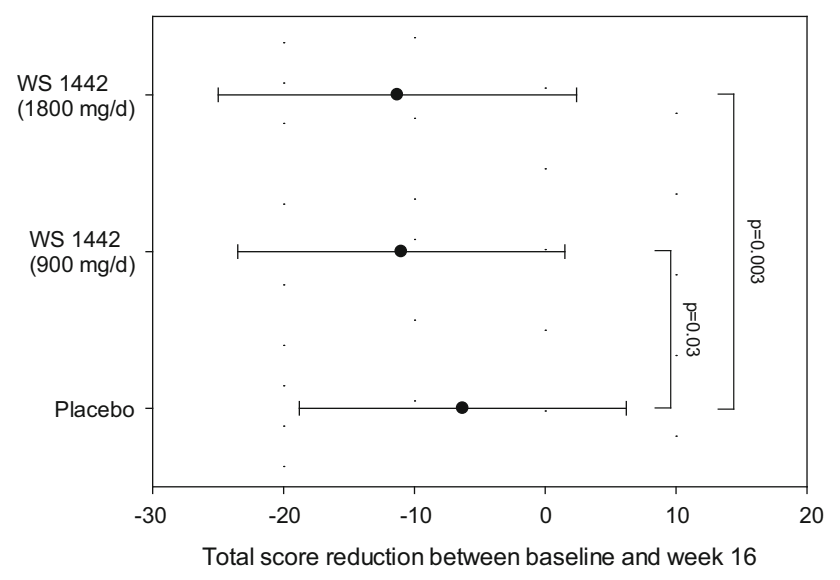

Fig. 6 Reduction in the total score of von Zerssen Complaints (means, standard deviations, and two-sided $p$ values; from [37], Fig. 4, and [81])

treatment, improvement of these symptoms was observed in 59\% of 63 patients exposed to WS 1442 and in $44 \%$ of 68 patients treated with placebo.

The EuroQol-5D questionnaire [63] was used in the study of Zick et al. [43] for assessing health-related QoL after 6 months' treatment with WS 1442 or placebo in 120 patients. No significant differences were found.

In an open-label, exploratory study, Härtel et al. [45] used the Kansas City Cardiomyopathy Questionnaire (KCCQ) [64], specifically developed for assessing QoL in patients with chronic heart failure, to investigate 140 patients with $\mathrm{HFpEF}$ undergoing 8 weeks' endurance exercise training with or without co-administration of WS 1442. The study was neither intended nor powered for demonstrating superiority of WS 1442 co-administration, and, moreover, the authors observed a ceiling effect in some of the KCCQ subscales already in patients undergoing exercise training alone so that further improvement in WS 1442-treated patients could hardly be expected. Nevertheless, in the Symptoms scale of the KCCQ, assessing the frequency and bothersomeness of edema, fatigue, and dyspnea as well as having to sleep in a sitting position or to use a supporting pillow to ameliorate shortness of breath, the summary score improved by $10 \pm 17$ points (mean \pm standard deviation) in the WS 1442 group compared to $5 \pm 14$ points in the control group. Moreover, each of the symptoms assessed showed a more favorable outcome in patients with co-administered WS 1442 (Fig. 7). The validity of the QoL results is limited by potential bias attributable to the open-label design of the study and may deserve confirmation in an adequately powered, double-blind, placebo-controlled trial. The incidence rate of AEs in patients receiving WS 1442 was lower than in those using exercise training alone (13 vs. 17\%).

\section{Benefit-Risk Assessment and Conclusions}

Although congestive heart failure may affect people of all ages, most of the burden is borne by individuals aged $\geq 65$ years, who account for more than $80 \%$ of the deaths and cases of the disease existing in the USA and Europe [65]. In this elderly, often multimorbid population, the resulting polypharmacy is associated with an exponential increase of the risk of adverse effects $[66,67]$ that may ultimately lead to increased mortality $[68,69]$. The use of drugs that have a favorable safety profile and a low potential for drug interactions is therefore crucial [70].

There is uniform agreement among researchers that Crataegus preparations cause few and mainly transient, non-serious adverse effects (e.g., [36, 45, 46, 52]). For WS 1442, no serious adverse reactions have been observed at all to date. In clinical trials, including a large-scale, longterm mortality study with patients receiving polydrug treatment for heart failure (e.g., ACE inhibitors, $\beta$-receptor blockers, spironolactone, digitalis, and nitrates in patients with LVEF $<35 \%$ ), no safety signals and no indications of possible drug interactions were observed [40], and an interaction with digoxin, which is widely used in HFrEF, has been excluded, thus allowing its safe co-administration [47]. It is therefore concluded that Crataegus extract WS 1442 has a very favorable safety profile even when administered as a part of a polydrug regimen.

The SPICE study did not demonstrate an additional beneficial effect of co-administered WS 1442 on mortality in addition to an existing anti-heart failure treatment regimen individually prescribed in accordance with applicable guidelines, but there is encouraging evidence that WS 1442 may reduce the risk of cardiac mortality and sudden cardiac death at least in a subgroup of patients (Figs. 2, 3) [40].

Randomized, controlled studies demonstrate that WS 1442 improves cardiac performance and exercise tolerance in patients with mild to moderately severe heart failure. Moreover, the herbal medicinal product has an ameliorating effect on heart failure emergent symptoms such as edema, dyspnea, and fatigue, and thus alleviates the disease burden of the patients and leads to an improvement of health-related QoL. Importantly, unlike for some other drugs which were also shown to improve such outcomes (e.g., [71]), no signals were observed that may adversely affect survival.

HFrEF is commonly defined as heart failure with LVEF $\leq 40 \%$, and HFpEF implies LVEF $\geq 50 \%$, whereas patients with LVEF between 41 and $49 \%$ may be regarded as suffering from borderline HFpEF (e.g., [51]). It should be noted that patients of both types of heart failure suffer from similar clinical symptoms. Among the studies considered in this review, the patients of the SPICE study [40], 
Fig. 7 Average change in frequency and intensity of heart failure symptoms assessed with the Kansas City

Cardiomyopathy Questionnaire (KCCQ) (from [45], Fig. 4)

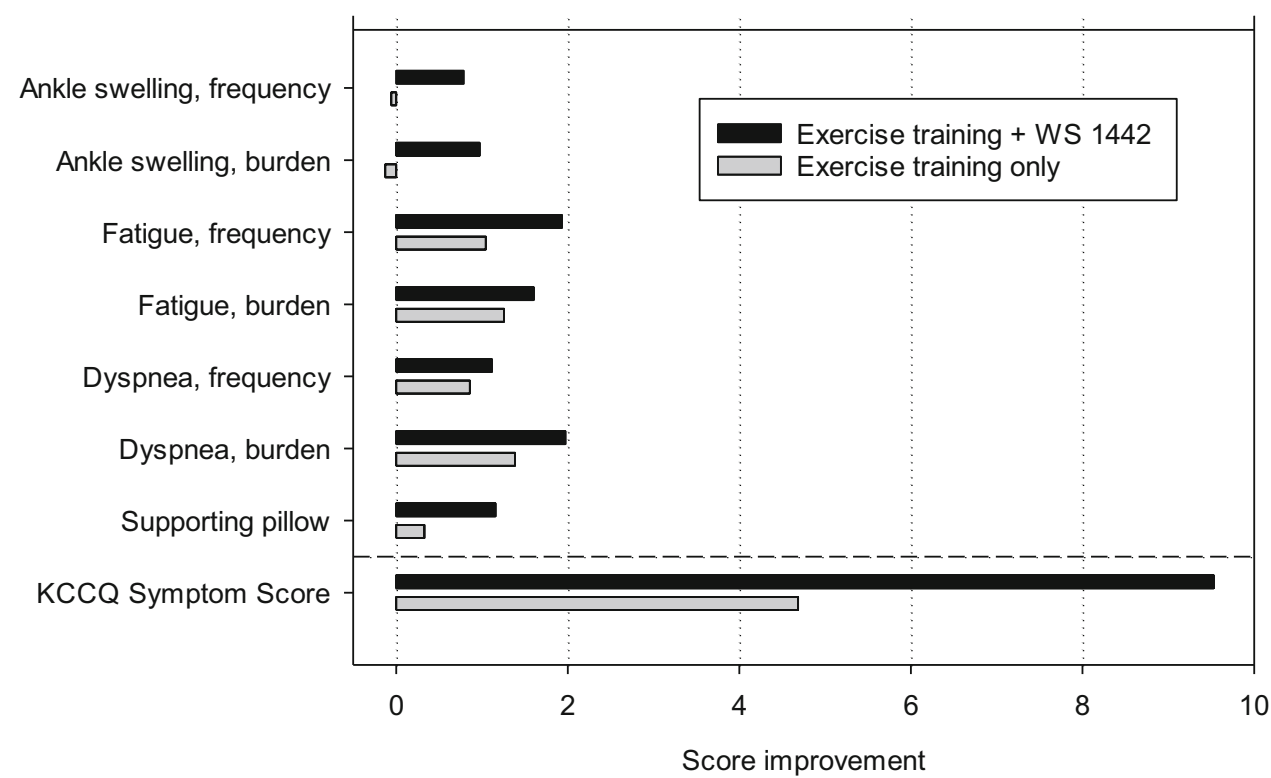

the HERB CHF study [43], and the study reported by Eichstädt et al. [60] suffered from HFrEF, whereas those of the study published by Härtel et al. [45] suffered from HFpEF. The protocols of the remaining trials reviewed for efficacy of WS 1442 did not include eligibility criteria for LVEF, but three trials required heart failure according to NYHA class II [55-57], whereas one required NYHA class III [37]. Although there is no clear association between the NYHA functional classification and LVEF [49], patients with class II heart failure have been found to mainly exhibit LVEF $>40 \%$ (e.g., [72]), and thus the majority of patients in these trials may likely have suffered from HFpEF.

We agree with the authors of the Cochrane review who concluded that "there is a significant benefit in symptom control and physiologic outcomes from hawthorn extract as an adjunctive treatment for chronic heart failure" [52] (p. 2). In HFrEF, WS 1442 has been shown to improve functional capacity and heart failure-associated symptoms without causing any safety issues despite long-term polypharmacy in a particularly vulnerable patient population. The improvement of functional capacity and symptoms is now recognized as an important objective of heart failure treatment, on one level with the reduction of mortality and hospitalization [49]. The administration of WS 1442 in addition to a guideline polydrug treatment in HFrEF appears to be justified since the anticipated benefit to the patients clearly outweighs the additional risk. In this context, it should be noted that the mortality studies confirming the efficacy of $\beta$-blockers, ACE inhibitors and mineralocorticoid receptor antagonists were all performed in patients with LVEF $\leq 35$ or $\leq 40 \%$ so that a beneficial effect in patients with LVEF $>40 \%$ is unproven [51]. Since HFpEF is commonly understood to require
LVEF $\geq 50 \%$, WS 1442 may help to close the therapeutic gap between HFrEF and HFpEF, but more studies are needed to corroborate this benefit

A favorable effect on mortality in HFpEF has not been demonstrated for any drug to date. Instead of proposing a gold standard treatment, current guidelines [49, 51] are therefore limited to recommending treatments targeting symptom amelioration. In this context, it is important to note that established standard drugs in heart failure treatment, including digitalis, angiotensin II receptor blockers (including irbesartan and candesartan) [73], angiotensinconverting enzyme inhibitors [74], ivabradine [75], ranolazine [76], and spironolactone, failed to improve the clinical outcome or had only moderate beneficial effects in HFpEF [77-80]. WS 1442, on the other hand, has been demonstrated to improve functional capacity, disabling symptoms, and health-related QoL and has a positive inotropic effect without causing specific adverse effects. In the absence of a gold standard therapy in HFpEF, WS 1442 may therefore be an important therapeutic option in addition to the current clinical standards.

We consider it a strength of our review that it provides a comprehensive overview of the available pre-clinical and clinical data for WS 1442 and thus enables a well-founded assessment of its benefits and risks in the treatment of heart failure. A limitation is that some of the evidence presented in our review originated from older, comparatively small, and partly uncontrolled research, so confirmation by controlled trials meeting current rigorous scientific standards would be highly welcome.

In conclusion, according to scientific evidence from randomized, controlled clinical trials and post-marketing surveillance data, Crataegus extract WS 1442 is a safe 
herbal medicinal product with proven, patient-relevant benefits regarding functional capacity, symptom control and health-related QoL in HFrEF and HFpEF. The observed clinical effects of the product can be explained by pre-clinical findings regarding its mode of action. WS 1442 has therefore been shown to have a positive benefit-risk profile for the treatment of both HFrEF and HFpEF as addon therapy to current clinical practices.

\section{Compliance with Ethical Standards}

Conflict of interest CJFH, WSC and JE have received honoraria from Dr. Willmar Schwabe GmbH \& Co. KG, Karlsruhe, Germany for conducting, and writing for, the SPICE study.

Ethical approval All procedures performed in studies involving human participants were in accordance with the ethical standards of the institutional and/or national research committee and with the 1964 Helsinki declaration and its later amendments or comparable ethical standards. This article does not contain any studies with animals performed by any of the authors.

Informed consent Informed consent was obtained from all individual participants included in the studies.

Open Access This article is distributed under the terms of the Creative Commons Attribution-NonCommercial 4.0 International License (http://creativecommons.org/licenses/by-nc/4.0/), which permits any noncommercial use, distribution, and reproduction in any medium, provided you give appropriate credit to the original author(s) and the source, provide a link to the Creative Commons license, and indicate if changes were made.

\section{References}

1. Inman T. Foundation for a new theory and practice of medicine. London: John Churchill; 1860.

2. Sokol DK. "First do no harm" revisited. BMJ. 2013;347:f6426. doi:10.1136/bmj.f6426.

3. Kaul R. Der Weißdorn. Botanik, Inhaltsstoffe, Qualitätskontrolle, Pharmakologie, Toxikologie und Klinik. Stuttgart: Wissenschaftliche Verlagsgesellschaft; 1998.

4. Jennings MC. Crataegus oxyacantha in the treatment of heart disease. N Y Med J. 1896;10(10):491-3.

5. Bundesgesundheitsamt. Monographie-Crataegi folium cum flore (Weißdornblätter mit Blüten). Bundesanzeiger. 1994;133 (19 July 1994):7360-1.

6. American Heart Association. 1994 Revisions to classification of functional capacity and objective assessment of patients with diseases of the heart. Circulation. 1994;90(1):644-5.

7. Committee on Herbal Medicinal Products (HMPC). European Union herbal monograph on Crataegus spp., folium cum flore. London: European Medicines Agency 2016 (5 April 2016). Report No.: EMA/HMPC/159075/2014 Contract No.: EMA/ HMPC/159075/2014.

8. Committee on Herbal Medicinal Products (HMPC). Assessment report on Crataegus spp., folium cum flore. London: European Medicines Agency 2016 (5 April 2016). Report No.: EMA/ HMPC/159076/2014 Contract No.: EMA/HMPC/159076/2014.

9. Koch E, Malek FA. Standardized extracts from hawthorn leaves and flowers in the treatment of cardiovascular disorders- preclinical and clinical studies. Planta Med. 2011;77(11):1123-8. doi:10.1055/s-0030-1270849.

10. Wang J, Xiong X, Feng B. Effect of Crataegus usage in cardiovascular disease prevention: an evidence-based approach. Evid Based Complement Alternat Med. 2013;2013:149363. doi:10.1155/2013/149363.

11. Schmidt-Schweda S, von Burstin J, Möllmann H, Wollner S, Holubarsch C. Der positiv inotrope Effekt des Crataegus Spezialextrakt WS 1442 in isolierten Myozyten aus menschlichem Vorhof- und Ventrikelmyokrad wird vorwiegend durch oligomere Procyanidine vermittelt. Z Kardiol. 2000;89(Suppl. 5):164, Abstract No. 797.

12. Schwinger RH, Pietsch M, Frank K, Brixius K. Crataegus special extract WS 1442 increases force of contraction in human myocardium cAMP-independently. J Cardiovasc Pharmacol. 2000;35(5):700-7.

13. Brixius K, Frank K, Münch G, Müller-Ehmsen J, Schwinger RHG. WS 1442 (Crataegus-Spezialextrakt) wirkt am insuffizienten menschlichen Myokard Kontraktionskraft-steigernd. Herz-Kreislauf. 1998;30:28-33.

14. Münch G, Brixius K, Frank K, Erdmann E. WS 1442 (extract of Crataegus species) increases force of contraction in human failing myocardium by inhibition of the $\mathrm{Na}+/ \mathrm{K}+$-ATPase. Circulation. 1997;96(Suppl.):I-729, Abstract No. 4090.

15. Krzeminski T, Chatterjee SS. Ischemia and early reperfusion induced arrythmias: beneficial effects of an extract of Crataegus oxyacantha L. Pharm Pharmacol Lett. 1993;3:45-8.

16. Koch E, Chatterjee SS. Crataegus extract WS-1442 enhances coronary flow in the isolated rat heart by endothelial release of nitric oxide. Naunyn-Schmiedeberg's Arch Pharmacol. 2000;4(Suppl.):R48 Abstract 180.

17. Brixius K, Willms S, Napp A, et al. Crataegus special extract WS 1442 induces an endothelium-dependent, NO-mediated vasorelaxation via eNOS-phosphorylation at serine 1177. Cardiovasc Drugs Ther. 2006;20(3):177-84.

18. Anselm E, Socorro VF, Dal-Ros S, Schott C, Bronner C, SchiniKerth VB. Crataegus special extract WS 1442 causes endothelium-dependent relaxation via a redox-sensitive Src- and Aktdependent activation of endothelial NO synthase but not via activation of estrogen receptors. J Cardiovasc Pharmacol. 2009;53(3):253-60. doi:10.1097/FJC.0b013e31819ccfc9.

19. Khemais-Benkhiat S, Idris-Khodja N, Ribeiro TP, et al. The redox-sensitive induction of the local angiotensin system promotes both premature and replicative endothelial senescence: preventive effect of a standardized Crataegus extract. J Gerontol A Biol Sci Med Sci. 2016;71(12):1581-90.

20. Idris-Khodja N, Auger C, Koch E, Schini-Kerth VB. Crataegus special extract WS ${ }^{\circledR} 1442$ prevents aging-related endothelial dysfunction. Phytomedicine. 2012;19(8-9):699-706. doi:10. 1016/j.phymed.2012.04.005.

21. Peters W, Druppel V, Kusche-Vihrog K, Schubert C, Oberleithner H. Nanomechanics and sodium permeability of endothelial surface layer modulated by hawthorn extract WS 1442. PLoS One. 2012;7(1):e29972. doi:10.1371/journal.pone.0029972.

22. Rieckeheer E, Schwinger RH, Bloch W, Brixius K. Hawthorn special extract WS ${ }^{\circledR} 1442$ increases red blood cell NO-formation without altering red blood cell deformability. Phytomedicine. 2011;19(1):20-4. doi:10.1016/j.phymed.2011.08.059.

23. Oberleithner H. Sodium selective erythrocyte glycocalyx and salt sensitivity in man. Pflugers Arch. 2015;467(6):1319-25. doi:10. 1007/s00424-014-1577-0.

24. Mävers WH, Hensel H. Veränderungen der lokalen Myokarddurchblutung nach oraler Gabe eines Crataegusextraktes bei nichtnarkotisierten Hunden. Arzneimittelforschung. 1974;24(5):783-5. 
25. Ribeiro TP, Auger C, Jabeen Q, et al. Intake of a standardized Crataegus extract prevents DOCA-salt-induced hypertension, and alteration of cardiac, vascular and renal structure and function in rats: Role of oxidative stress. Clin Res Cardiol. 2015;104(Suppl. 1):Abstract P1828. doi:10.1007/s00392-0151100-4.

26. Kurcok A. Ischemia- and perfusion-induced cardiac injury: effects of two flavonoid containing plant extracts possessing radical scavenging properties. Naunyn-Schmiedeberg's Arch Pharmacol. 1992;345(Suppl.):R81 Abstract 322.

27. Veveris M, Koch E, Chatterjee SS. Crataegus special extract WS 1442 improves cardiac function and reduces infarct size in a rat model of prolonged coronary ischemia and reperfusion. Life Sci. 2004;74(15):1945-55. doi:10.1016/j.lfs.2003.09.050.

28. Chatterjee SS, Koch E, Jaggy H, Krzeminski T. In-vitro- und Invivo-Untersuchungen zur kardioprotektiven Wirkung von oligomeren Procyanidinen in einem Crataegus-Extrakt aus Blättern mit Blüten. Arzneimittelforschung. 1997;47(7):821-5.

29. Koch E, Spörl-Aich G. Oral treatment with the Crataegus special extract WS ${ }^{\circledR} 1442$ inhibits cardiac hypertrophy in rats with DOCA-salt or aortic banding induced hypertension. Planta Med. 2006;72(11):P_265. doi:10.1055/s-2006-950065.

30. Hwang HS, Bleske BE, Ghannam MM, et al. Effects of hawthorn on cardiac remodeling and left ventricular dysfunction after 1 month of pressure overload-induced cardiac hypertrophy in rats. Cardiovasc Drugs Ther. 2008;22(1):19-28. doi:10.1007/ s10557-008-6082-2.

31. Hwang HS, Boluyt MO, Converso K, Russell MW, Bleske BE. Effects of hawthorn on the progression of heart failure in a rat model of aortic constriction. Pharmacotherapy. 2009;29(6):639-48. doi:10.1592/phco.29.6.639.

32. Koch E, Chatterjee SS. Crataegus extract WS-1442 compensates the decrease of cardiac output in endotoxemic rats. In: 3rd symposium on cytokines and apoptosis in the cardiovascular system; 27-28 Jan 2000; Halle. 2000.

33. Brixius K, Willms S, Schwinger RH. Grundlage für die Therapie kardiovaskulärer Erkrankungen: Zelluläre und molekulare Wirkmechanismen von Crataegus-Extrakt. Pharm Unserer Zeit. 2005;34(1):48-51. doi:10.1002/pauz.200400104.

34. Koch E, Lanzendörfer-Goossens H, Weibezahn C. CrataegusSpezialextrakt WS ${ }^{\circledR} \quad 1442$ hemmt die Sekretion von Apolipoprotein B100 (ApoB) und erhöht die Transkription des Low-Density Lipoproteinrezeptors (LDL-R) in humanen HepG2Zellen. Z Phytother. 2006;27(S 1):P17. doi:10.1055/s-2006954919.

35. Hecker-Niediek AE. Untersuchung zur Biogenese, Markierung und Pharkakokinetik der Procyanidine aus Crataegus-Species. Marburg: Philipps-Universität; 1983.

36. Daniele C, Mazzanti G, Pittler MH, Ernst E. Adverse-event profile of Crataegus spp.: a systematic review. Drug Saf. 2006;29(6):523-35.

37. Tauchert M. Efficacy and safety of Crataegus extract WS 1442 in comparison with placebo in patients with chronic stable New York Heart Association class-III heart failure. Am Heart J. 2002;143(5):910-5.

38. Tauchert M, Gildor A, Lipinski J. Einsatz des hochdosierten Crataegusextraktes WS 1442 in der Therapie der Herzinsuffizienz Stadium NYHA II. Herz. 1999;24(6):465-74.

39. Holubarsch CJ, Colucci WS, Meinertz T, Gaus W, Tendera M. Survival and Prognosis: Investigation of Crataegus Extract WS 1442 in congestive heart failure (SPICE) — rationale, study design and study protocol. Eur J Heart Fail. 2000;2(4):431-7.

40. Holubarsch CJ, Colucci WS, Meinertz T, Gaus W, Tendera M. The efficacy and safety of Crataegus extract WS 1442 in patients with heart failure: the SPICE trial. Eur J Heart Fail. 2008;10(12):1255-63. doi:10.1016/j.ejheart.2008.10.004.
41. Chaudhry GM, Haffajee CI. Antiarrhythmic agents and proarrhythmia. Crit Care Med. 2000;28(10 Suppl):N158-64.

42. Podrid PJ. Proarrhythmia, a serious complication of antiarrhythmic drugs. Curr Cardiol Rep. 1999;1(4):289-96.

43. Zick SM, Vautaw BM, Gillespie B, Aaronson KD. Hawthorn extract randomized blinded chronic heart failure (HERB CHF) trial. Eur J Heart Fail. 2009;11(10):990-9. doi:10.1093/eurjhf/ hfp116.

44. Zick SM, Gillespie B, Aaronson KD. The effect of Crataegus oxycantha special extract WS 1442 on clinical progression in patients with mild to moderate symptoms of heart failure. Eur J Heart Fail. 2008;10(6):587-93. doi:10.1016/j.ejheart.2008.04. 008.

45. Härtel S, Kutzner C, Westphal E, et al. Effects of endurance exercise training and Crataegus extract WS ${ }^{\circledR} 1442$ in patients with heart failure with preserved ejection fraction-a randomized controlled trial. Sports. 2014;2(3):59-75. doi:10.3390/ sports2030059.

46. Koch E, Busse WR, Juretzek W, Chevts V. Hawthorn. In: Coates PM, Betz JM, Blackman MR, Cragg GM, Levine M, Moss J, et al., editors. Encyclopedia of dietary supplements. 2nd ed. New York: Informa Healthcare; 2010. p. 411-22.

47. Tankanow R, Tamer HR, Streetman DS, et al. Interaction study between digoxin and a preparation of hawthorn (Crataegus oxyacantha). J Clin Pharmacol. 2003;43(6):637-42.

48. Dickstein K, Cohen-Solal A, Filippatos G, et al. ESC guidelines for the diagnosis and treatment of acute and chronic heart failure 2008. The Task Force for the Diagnosis and Treatment of Acute and Chronic Heart Failure 2008 of the European Society of Cardiology. Developed in collaboration with the Heart Failure Association of the ESC (HFA) and endorsed by the European Society of Intensive Care Medicine (ESICM). Eur J Heart Fail. 2008;10(10):933-89. doi:10.1016/j.ejheart.2008.08.005.

49. McMurray JJ, Adamopoulos S, Anker SD, et al. ESC guidelines for the diagnosis and treatment of acute and chronic heart failure 2012: the Task Force for the Diagnosis and Treatment of Acute and Chronic Heart Failure 2012 of the European Society of Cardiology. Developed in collaboration with the Heart Failure Association (HFA) of the ESC. Eur J Heart Fail. 2012;14(8):803-69. doi:10.1093/eurjhf/hfs105.

50. Ekman I, Cleland JG, Andersson B, Swedberg K. Exploring symptoms in chronic heart failure. Eur J Heart Fail. 2005;7(5):699-703. doi:10.1016/j.ejheart.2005.07.003.

51. Yancy CW, Jessup M, Bozkurt B, et al. 2013 ACCF/AHA guideline for the management of heart failure: executive summary: a report of the American College of Cardiology Foundation/American Heart Association Task Force on practice guidelines. Circulation. 2013;128(16):1810-52. doi:10.1161/CIR. 0b013e31829e8807.

52. Guo R, Pittler MH, Ernst E. Hawthorn extract for treating chronic heart failure. Cochrane Database Syst Rev. 2008(1):CD005312. doi:10.1002/14651858.CD005312.pub2.

53. Bödigheimer K, Chase D. Wirksamkeit von Weißdorn-Extrakt in der Dosierung 3 mal $100 \mathrm{mg}$ täglich. Multizentrische Doppelblindstudie mit 85 herzinsuffizienten Patienten im Stadium NYHA II. Münch Med Wschr. 1994;136(Suppl. 1):S7-11.

54. Hanak T, Brückel MH. Behandlung von leichten stabilen Formen der Angina pectoris mit Crataegutt $^{\circledR}$ novo. Therapiewoche. 1983;33:4331-3.

55. Zapfe jun G. Clinical efficacy of Crataegus extract WS 1442 in congestive heart failure NYHA class II. Phytomedicine. 2001;8(4):262-6.

56. Leuchtgens H, Crataegus-Spezialextrakt WS. 1442 bei Herzinsuffizienz NYHA II. Fortschr Med. 1993;111:352-4.

57. Weikl A, Assmus KD, Neukum-Schmidt A, et al. CrataegusSpezialextrakt WS 1442. Objektiver Wirksamkeitsnachweis bei 
Patienten mit Herzinsuffizienz (NYHA II). Fortschr Med. 1996;114(24):291-6.

58. O'Connolly M, Bernhöft G, Bartsch G. Behandlung älterer, multimorbider Patienten mit stenokardischen Beschwerden. Eine placebokontrollierte Cross-over-Doppelblindstudie mit Crataegutt ${ }^{\circledR}$ novo. Therapiewoche. 1987;37:3587-600.

59. O'Connolly M, Jansen W, Bernhöft G, Bartsch G. Behandlung der nachlassenden Herzleistung. Therapie mit standardisiertem Crataegus-Extrakt im hoheren Lebensalter. Fortschr Med. 1986;104(42):805-8.

60. Eichstädt H, Störk T, Möckel M, Danne O, Funk P, Köhler S. Wirksamkeit und Verträglichkeit von Crataegus-Extrakt WS 1442 bei herzinsuffizienten Patienten mit eingeschränkter linksventrikulärer Funktion. Perfusion. 2001;14:212-7.

61. von Zerssen D. Die Beschwerden-Liste als Test. Therapiewoche. 1971;21:1908-20.

62. Siegrist J, Junge A. Lebensqualität unter antihypertensiver Therapie. Herz. 1987;12(Suppl. I):10-5.

63. EuroQol G. EuroQol-a new facility for the measurement of health-related quality of life. Health Policy. 1990;16(3):199-208.

64. Green CP, Porter CB, Bresnahan DR, Spertus JA. Development and evaluation of the Kansas City Cardiomyopathy Questionnaire: a new health status measure for heart failure. J Am Coll Cardiol. 2000;35(5):1245-55.

65. Bui AL, Horwich TB, Fonarow GC. Epidemiology and risk profile of heart failure. Nat Rev Cardiol. 2011;8(1):30-41. doi:10. 1038/nrcardio.2010.165.

66. Goldberg RM, Mabee J, Chan L, Wong S. Drug-drug and drugdisease interactions in the ED: analysis of a high-risk population. Am J Emerg Med. 1996;14(5):447-50. doi:10.1016/S07356757(96)90147-3.

67. Nishtala PS, Salahudeen MS. Temporal trends in polypharmacy and hyperpolypharmacy in older New Zealanders over a 9-year period: 2005-2013. Gerontology. 2015;61(3):195-202. doi:10. $1159 / 000368191$.

68. Gómez C, Vega-Quiroga S, Bermejo-Pareja F, Medrano MJ, Louis ED, Benito-León J. Polypharmacy in the elderly: a marker of increased risk of mortality in a population-based prospective study (NEDICES). Gerontology. 2015;61(4):301-9. doi:10.1159/ 000365328

69. Maher RL Jr, Hanlon JT, Hajjar ER. Clinical consequences of polypharmacy in elderly. Expert Opin Drug Saf. 2014;13(1):57-65. doi:10.1517/14740338.2013.827660.

70. Wickop B, Langebrake C. Gute Verordnungspraxis bei älteren Patienten. Ther Umsch. 2014;71(6):366-73. doi:10.1024/00405930/a000524.
71. Packer M, Narahara KA, Elkayam U, et al. Double-blind, placebo-controlled study of the efficacy of flosequinan in patients with chronic heart failure. Principal Investigators of the REFLECT Study. J Am Coll Cardiol. 1993;22(1):65-72.

72. Alhusseiny AH, Al-Nimer MSM, Latif II, Ibrahim AK. Heart failure: discrepancy between NYHA functional classification, serum NT-pro brain natriuretic peptide and ejection fraction. Eur J Gen Med. 2013;10(1):26-31.

73. Yusuf S, Pfeffer MA, Swedberg K, et al. Effects of candesartan in patients with chronic heart failure and preserved left-ventricular ejection fraction: the CHARM-Preserved Trial. Lancet. 2003;362(9386):777-81. doi:10.1016/S0140-6736(03)14285-7.

74. Cleland JG, Tendera M, Adamus $\mathrm{J}$, et al. The perindopril in elderly people with chronic heart failure (PEP-CHF) study. Eur Heart J. 2006;27(19):2338-45. doi:10.1093/eurheartj/ehl250.

75. Komajda M, Isnard R, Cohen-Solal A, et al. Effect of ivabradine in patients with heart failure with preserved ejection fraction: the EDIFY randomized placebo-controlled trial. Eur J Heart Fail. 2017;. doi:10.1002/ejhf.876.

76. Maier LS, Layug B, Karwatowska-Prokopczuk E, et al. RAnoLazIne for the treatment of diastolic heart failure in patients with preserved ejection fraction: the RALI-DHF proof-of-concept study. JACC Heart Fail. 2013;1(2):115-22. doi:10.1016/j.jchf. 2012.12.002.

77. Ahmed A, Rich MW, Fleg JL, et al. Effects of digoxin on morbidity and mortality in diastolic heart failure: the ancillary digitalis investigation group trial. Circulation. 2006;114(5):397-403. doi:10.1161/CIRCULATIONAHA.106.628347.

78. Edelmann F, Wachter R, Schmidt AG, et al. Effect of spironolactone on diastolic function and exercise capacity in patients with heart failure with preserved ejection fraction: the Aldo-DHF randomized controlled trial. JAMA. 2013;309(8):781-91. doi:10. 1001/jama.2013.905.

79. Massie BM, Carson PE, McMurray JJ, et al. Irbesartan in patients with heart failure and preserved ejection fraction. $\mathrm{N}$ Engl $\mathrm{J}$ Med. 2008;359(23):2456-67. doi:10.1056/NEJMoa0805450.

80. Pitt B, Pfeffer MA, Assmann SF, et al. Spironolactone for heart failure with preserved ejection fraction. $\mathrm{N}$ Engl $\mathrm{J}$ Med. 2014;370(15):1383-92. doi:10.1056/NEJMoa1313731.

81. Härtel S, Kutzner C, Burkart M, Bös K. Einfluss von Training und Crataegus-Extrakt WS ${ }^{\circledR} 1442$ auf körperliche Leistungsfähigkeit und Lebensqualität bei leichter Herzinsuffizienzeine randomisierte kontrollierte Studie. Z Phytother. 2012;33:P15. doi:10.1055/s-0032-1313255. 